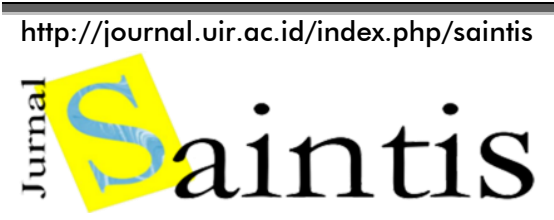

Volume 19 Nomor 2, Oktober 2019 : 79-88

\title{
Waste Konstruksi: Identifikasi Potensi dan Penyebabnya Pada Proyek Perumahan Di Pekanbaru
}

\author{
Construction Waste: Identification of Potential and Its Causes in Housing Project in Pekanbaru
}

\author{
Sapitri ${ }^{1, *}$, Firdaus $^{2}$ \\ ${ }_{1}$ Program Studi Teknik Sipil, Universitas Islam Riau, Jl. Kaharuddin Nasution No. 113, Pekanbaru, Indonesia \\ ${ }^{2}$ Program Studi Perencanaan Wilayah dan Kota, Universitas Islam Riau, Jl. Kaharuddin Nasution No. 113, Pekanbaru, Indonesia
}

\author{
* Penulis korespondensi: spitriap@eng.uir.ac.id \\ Tel.: +62-85353399057 \\ Diterima: 7 Oktober 2019; Direvisi: 18 Oktober 2019; Disetujui: 30 Oktober 2019. \\ DOI: 10.25299/saintis.2019.vol19(02).3904
}

\section{Abstrak}

Waste merupakan salah satu penyebab rendahnya produktivitas. Besarnya potensi waste tentu saja akan merugikan owner ataupun kontraktor. Waste pada industri perumahan dapat mempengaruhi nilai jual rumah itu sendiri. Potensi waste material yang muncul pada proses pembangunan, penting untuk diidentifikasi dan dicari penyebabnya. Tujuan dari penelitian ini adalah mengidentifikasikan waste pada industri konstruksi (proyek perumahan) beserta sumber penyebab waste tersebut. Penelitian bersifat kuantitatif dan data primer dikumpulkan dengan bantuan instrumen kuesioner. Responden yang terlibat seluruhnya adalah pengawas lapangan/penanggung jawab lapangan proyek perumahan. The Statistical Package for Social Sciences (SPSS) dan fishbone diagram digunakan sebagai alat analisis variabel dan indikator penyebab waste. Secara keseluruhan, hasil identifikasi penelitian menunjukkan bahwa material yang berpotensi ditemui pada proyek pembangunan perumahan di Pekanbaru yaitu material kayu dan batu bata (berpotensi sedang), material keramik, genteng, besi beton, cat, tanah, batu, pasir dan plesteran (berpotensi rendah) dan, cardboard packaging, plastik, kaca, metal, aspal dan plafond (berpotensi sangat rendah). Terdapat beberapa variable penyebab waste. Variabel-variabel tersebut terkait dengan sumber daya yang dibutuhkan selama proses pengerjaan proyek. Sumber penyebab waste yang berkonstribusi selama proses produksi secara signifikan dipengaruhi oleh variabel: alat/mesin sebesar 0,885, metode kerja sebesar 0,873, material sebesar 0,866, manpower sebesar 0,821 , dan lingkungan sebesar 0,808 . Satu sumber variabel dapat mempengaruhi variabel yang lain, sehingga sangat penting untuk memperhatikan penyebab waste agar produktivitas pekerjaan dilapangan tidak terganggu.

Kata Kunci: waste, identifikasi, penyebab waste, perumahan, fishbone diagram

\begin{abstract}
Waste is one of the causes of low productivity. The potential of waste will certainly harm the owner or contractor. Waste in housing industry can affect the sale price of the house. The potential of material waste in construction process is important to identify and need to find its cause. The purpose of this study is to identify waste in the construction industry (housing project) along with the source of the cause of the waste. Quantitative research is conducted and primary data were collected with questionnaire as the instrument. All respondents involved were supervisor. The Statistical Package for Social Sciences (SPSS) and fishbone diagrams are used as a tool for analyzing variables and indicators of the causes of waste. Overall, the result of research identification shows that the potential material in housing construction projects in Pekanbaru, namely wood and brick material (medium potential), ceramic, roof tile, steel, paint, soil, stone, sand and plastering (low potential) and, cardboard packaging, plastic, glass, metal, asphalt and ceiling (very low potential). There are several variables that cause waste. These variables are related to the resources that needed during the construction process. The sources of waste causes that contribute during the production process are significantly influenced by variables, i.e. tools / machines at 0.885, work methods at 0.873, materials at 0.866, manpower at 0.821, and the environment at 0.808. One source of variables can affect other variables, so it is necessary to pay attention to the waste causes so that work productivity uninterrupted.
\end{abstract}

Keywords: waste, identification, cause of waste, housing, fishbone diagram

\section{PENDAHULUAN}

Industri (proyek) konstruksi masih dipandang sebagai suatu peluang bisnis yang menjanjikan profit besar. Hal ini dapat dilihat dari pasar konstruksi yang terus tumbuh dan banyaknya pelaku usaha yang terjun di sektor ini. Tidak ketinggalan pula pertumbuhan industri konstruksi perumahan di kota Pekanbaru. Real Estate Indonesia (REI) menargetkan akan membangun 15 ribu rumah di Riau pada tahun 2018. Idealnya, peningkatan akan kebutuhan hunian yang diakomodir oleh penyedia (developer) harus di iringi pula dengan peningkatan produktivitas agar harga rumah di pasaran dapat lebih terjangkau oleh masyarakat.

Waste merupakan salah satu penyebab rendahnya produktivitas. Waste dapat didefenisikan sebagi ketidak-efisienan dari akibat adanya penggunaan alat, material, tenaga kerja atau modal dalam jumlah yang besar dari yang seharusnya dikeluarkan untuk memproduksi sebuah bangunan [1]. Secara umum, waste merupakan pemborosan, 
tidak hanya berupa material yang terbuang, tetapi juga sumber daya lain seperti waktu, energi (manpower), serta alat yang tidak memberikan nilai tambah. Selanjutnya dipertegas bahwa waste ini sesuatu yang tidak dapat memberikan nilai (value) baik bagi pemilik proyek (owner), rekanan (client) maupun pengguna (user)-nya. Waste yang muncul selama siklus proyek harus diminimalisir dan dimanage dengan baik sehingga dapat memberikan nilai tambah dan tentunya akan mempengaruhi nilai jual hunian tersebut karena telah berkurangnya biaya produksi.

Terdapat banyak waste pada industri konstruksi. Berdasarkan proporsi usaha konstruksi, yang berpotensi menjadi waste yaitu sebesar 55$65 \%$ [2]. Besarnya potensi waste ini tentu saja akan merugikan owner ataupun kontraktor. Potensi waste dapat muncul dari berbagai material yang digunakan dan dari aktivitas/ proses pembangunan perumahan itu sendiri. Potensi waste material antara lain; material keramik, kayu, besi beton [3][4][5], genteng, cat [3]. Penyebab utama waste untuk material kayu, genteng, dan besi beton adalah karena kesalahan pekerja. Sedangkan pada material cat adalah karena perubahan speksifikasi mendadak [3]. Material lain yang berpotensi besar menimbulkan waste yaitu batu bata [4][5], beton, plesteran [5][[6], bekisting, acian, serta pemasangan perabot/asesoris [5]. Potensi waste pada residential building lainnya yaitu; tanah dan batu, cardboard packaging, plastik, kaca, metal, dan aspal [6].

Melihat potensi waste pada perumahan di atas, maka perlu untuk diatur sedemikian rupa agar waste tersebut dapat diminimalisir dan dimitigasi dengan baik, sehingga produktifitas sumber daya proyek dapat diberdayakan dengan maksimal. Lean construction (konstruksi ramping) adalah konsep yang memiliki kapasitas untuk maju dan berkembang. Prinsip konstruksi ramping fokus pada meminimalisasi material dan limbah yang berkontribusi pada pembangunan [7]. Construction Institute mendefinisikan Lean Construction sebagai suatu proses yang berlangsung terus menerus dari proses menghilangkan waste, memenuhi kebutuhan konsumen, fokus pada aliran informasi/material, dan mencapai kesempurnaan dalam pelaksanaan pembangunan dalam proyek [8].

Tujuan dari penelitian ini adalah mengidentifikasikan waste pada industri konstruksi (proyek perumahan) beserta sumber penyebab waste tersebut.

\section{METODOLOGI}

Untuk mencapai tujuan pada penelitian ini, maka terdapat beberapa tahapan yang dilakukakun. Adapu tahapan tersebut yaitu:
1. Melakukan proses identifikasi variabel dan indikator dari beberapa penelitian sebelumnya, yang selanjutnya dikembangkan menjadi instrumen pengambilan data, yaitu berupa kuesioner.

2. Mengidentifikasi waste yang berpotensi besar muncul pada proyek perumahan di Pekanbaru.

3. Mengidentifikasi sumber penyebab waste.

\section{Pengumpulan Data}

Teknik pengambilan data yang digunakan yaitu teknik survey. Data awal yang dikumpulkan yaitu data sekunder, berupa data pembangunan perumahan di wilayah Pekanbaru yang terdaftar pada Real Estate Indonesia Wilayah Pekanbaru (REI). Fokus penelitian ini adalah rumah yang tidak mendapat subsidi (non-subsidi) pemerintah. Hasil klasifikasi perumahan di Pekanbaru dapat dilihat pada Gambar 1.

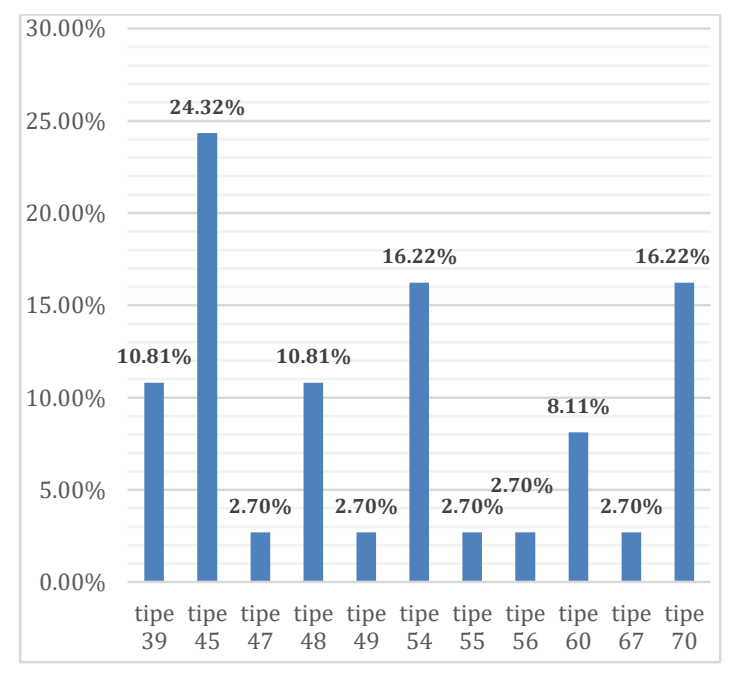

Gambar 1. Persentase Pembangunan Perumahan di Pekanbaru (data Mei 2019)

Sumber: REI, diolah.

Pada Gambar 1 dapat dilihat tipe non subsidi yang mendominasi yaitu tipe 45 sebesar 24\%. Selanjutnya, tipe rumah tersebut dijadikan sasaran penelitian. Pengambilan data telah dilakukan dalam rentang waktu bulan Juni - Augustus. Terdapat 6 proyek perumahan yang dikerjakan di Pekanbaru dalam rentang waktu tersebut, dengan 8 orang responden.

Kuesioner yang digunakan dalam pengambilan data yaitu kuisioner potensi waste dan kuesioner penyebab sumber waste berdasarkan sumber daya (manpower, material, metode, alat, dan lingkungan/environment). Untuk membantu responden dalam menentukan potensi waste, maka disediakan skala likert 1-5 dari Sangat Rendah hingga Sangat Tinggi.

$$
\begin{array}{ll}
1 & =\text { Sangat Rendah } \\
2 & =\text { Rendah (R) } \\
3 & =\text { Sedang (S) }
\end{array}
$$


4 = Tinggi $(\mathrm{T})$

5 = Sangat Tinggi (ST)

Skala sangat rendah maknanya waste material jarang ditemui ada/terjadi di lokasi proyek, skala rendah maknanya kadang waste material sada/terjadi di lokasi proyek namun lebih sering tidak terjadi, skala sedang maknanya waste material ditemui ada/terjadi cukup sering di lokasi proyek, skala tinggi maknanya waste material sering ditemui ada/terjadi pada setiap proyek, dan skala sagat tinggi maknanya waste material selalu ditemui ada/terjadi pada setiap lokasi proyek.

Adapun untuk identifikasi penyebab waste berdasarkan sumber daya, juga digunakan skala likert 1-5. Responden memberikan respon dengan cara menghubungkan (berdasarkan pengalaman/ persepsi mereka dilapangan) seberapa tinggi suatu item penyebab waste berpengaruh terhadap variabelnya.

$$
\begin{array}{ll}
1 & =\text { Sangat Rendah } \\
2 & =\text { Rendah (R) } \\
3 & =\text { Sedang (S) } \\
4 & =\text { Tinggi (T) } \\
5 & =\text { Sangat Tinggi (ST) }
\end{array}
$$

Identifikasi penyebab waste selama aktivitas/proses pembangunan dikelompokkan kedalam 5 variabel penyebab, yaitu manpower, material, metode, alat/mesin dan environment. Ke-5 penyebab ini memiliki beberapa indikator. Secara keseluruhan terdapat 27 item indikator penyebab waste dari lima variable yang digunakan. Indikator dari masing-masing variabel yang digunakan dalam

\begin{tabular}{|c|c|c|}
\hline 2.2 & Material rusak. & Mat2 \\
\hline 2.3 & $\begin{array}{l}\text { Kualitas material rendah / } \\
\text { buruk. }\end{array}$ & Mat3 \\
\hline 2.4 & $\begin{array}{l}\text { Keterlambatan material tiba di } \\
\text { lokasi. }\end{array}$ & Mat4 \\
\hline 2.5 & $\begin{array}{l}\text { Penyimpanan material yang } \\
\text { buruk. }\end{array}$ & Mat5 \\
\hline 3. & Metode & \\
\hline 3.1 & SOP tidak ada. & Met1 \\
\hline 3.2 & $\begin{array}{l}\text { Inkonsisten metode kerja } \\
\text { (metode kerja berubah-ubah). }\end{array}$ & Met2 \\
\hline 3.3 & $\begin{array}{llr}\text { Metode } & \text { konstruksi } & \text { yang } \\
\text { digunakan } & \text { tidak tepat / tidak } \\
\text { sesuai. } & \\
\end{array}$ & Met3 \\
\hline 3.4 & Perubahan desain. & Met4 \\
\hline 3.5 & $\begin{array}{l}\text { Perencanaan dan penjadwalan } \\
\text { yang buruk. }\end{array}$ & Met5 \\
\hline 4. & Alat/ Mesin & \\
\hline 4.1 & Alat rusak. & Al1 \\
\hline 4.2 & $\begin{array}{l}\text { Perbaikan alat membutuhkan } \\
\text { waktu yang cukup lama. }\end{array}$ & $\mathrm{Al} 2$ \\
\hline 4.3 & $\begin{array}{l}\text { Alat yang digunakan tidak } \\
\text { sesuai. }\end{array}$ & $\mathrm{Al} 3$ \\
\hline 4.4 & $\begin{array}{l}\text { Alat terlalu konvensional / } \\
\text { kuno. }\end{array}$ & $\mathrm{Al} 4$ \\
\hline 4.5 & Alat kurang. & Al5 \\
\hline 5. & Environment / Lingkungan & \\
\hline 5.1 & Cuaca (hujan). & Env1 \\
\hline 5.2 & Masyarakat yang complain. & Env2 \\
\hline 5.3 & Kondisi lokasi. & Env3 \\
\hline 5.4 & $\begin{array}{l}\text { Kerusakan/kehilangan akibat } \\
\text { pihak lain. }\end{array}$ & Env4 \\
\hline
\end{tabular}
mengumpulkan data pada penelitian ini dapat dilihat pada tabel 1 .

Tabel 1. Variabel dan Indikator Penyebab Waste

\begin{tabular}{lll}
\hline No. & \multicolumn{1}{c}{ Sumber Waste } & Kode \\
\hline 1. & Manpower & \\
\hline 1.1 & Skill yang rendah. & Man1 \\
\hline 1.2 & $\begin{array}{l}\text { Tidak / kurang pengalaman } \\
\text { kerja. }\end{array}$ & Man2 \\
\hline 1.3 & $\begin{array}{l}\text { Tidak mengikuti prosedur } \\
\text { kerja. }\end{array}$ & Man3 \\
\hline 1.4 & $\begin{array}{l}\text { Adanya keterbatasan fisik } \\
\text { (cidera lama). }\end{array}$ & Man4 \\
\hline 1.5 & $\begin{array}{l}\text { Tindakan kasar pekerja } \\
\text { sehingga material rusak. }\end{array}$ & Man5 \\
\hline 1.6 & $\begin{array}{l}\text { Kecerobohan / ketidak-telitian } \\
\text { dan kesalahan pekerja di } \\
\text { lapangan. }\end{array}$ & Man6 \\
\hline 1.7 & $\begin{array}{l}\text { Pemasok (supplier) terlambat } \\
\text { mengirim barang. }\end{array}$ & Man7 \\
\hline No. & Sumber Waste & Kode \\
\hline 1.8 & $\begin{array}{l}\text { Teamwork yang kurang / tidak } \\
\text { solid. }\end{array}$ & Man8 \\
\hline 2. & Material & Pembelian material tidak \\
\hline 2.1 & $\begin{array}{l}\text { Mat1 } \\
\text { (material yang salah). }\end{array}$ & \\
\hline
\end{tabular}

\section{Analisis Data}

Untuk kategorisasi hasil keseluruhan data yang diperoleh, maka di gunakan rumus Range pada persamaan (1) berikut:

$$
\text { Range }=\left(\frac{\text { Skor Maksimum-Skor Minimum }}{\text { Jumlah Kategori }}\right)-1
$$

Sedangkan untuk penyebab waste data dianalisis dengan bantuan The Statistical Package for Social Sciences (SPSS). SPSS digunakan untuk mengukur validitas dan reliabilitas serta melihat keeratan hubungan (korelasi) antar item indikator penyebab waste. Validitas dan reliabilitas adalah dua fitur penting dan mendasar dalam evaluasi segala instrumen pengukuran atau alat untuk penelitian yang baik [9]. Dikatakan valid apabila mampu mengukur apa yang diinginkan [10]. Salah satu metode yang digunakan untuk menguji validitas adalah menggunakan Corrected Item - Total Correlation. Sebuah item pertanyaan dikatakan valid jika nilai korelasinya lebih besar dari nilai korelasi tabel pada tingkat signifikan umumnya $5 \%$.

Kriteria pertanyaan valid jika nilai korelasi total lebih besar dari $r$ tabel. Kriteria penilaian uji validitas yaitu sebagai berikut:

a) Jika $r$ hitung $>r$ tabel maka variabel pernyataan dikatakan valid 
b) Jika $r$ hitung $<r$ tabel maka variabel pernyataan dikatakan tidak valid

Reliabilitas merujuk pada instrumen yang digunakan dalam penelitian untuk medapatkan informasi dapat dipercaya sebagai alat pengumpulan data dan mampu mengungkap informasi yang sebenarnya dilapangan [11]. Klasifikasi rentang nilai Alpha Cronbach's yaitu:

- alpha $<0.50$ reliabilitas rendah

- $0.50<$ alpha $<0.70$ reliabilitas moderat

- alpha > 0.70 maka reliabilitas mencukupi (sufficient reliability)

- alpha > 0.80 maka reliabilitas kuat

- alpha > 0.90 maka reliabilitas sempurna

Semakin kecil nilai alpha menunjukkan semakin banyak item yang tidak reliabel. Standar yang digunakan adalah alpha > 0.70 yang realibilitasnya cukup dapat dipercaya sebagai alat pengambilan data (sufficient reliability).

Selanjutnya untuk melihat keeratan hubungan, maka digunakan korelasi spearman. Uji korelasi spearman adalah uji statistik yang ditujukan untuk mengetahui hubungan antara dua atau lebih variabel berskala ordinal. Interval kategorisasi kekuatan hubungan korelasi yang digunakan yaitu berdasarkan [12] .

- Tidak ada korelasi

$: 0$

- Korelasi sangat lemah

: $0,01-0,25$

- Korelasi sangat cukup

: $0,26-0,50$

- Korelasi kuat

: $051-0,75$

- Korelasi sangat kuat

- Korelasi sempurna

: $0,76-0,99$

$: 1$

Hasil score korelasi spearman yang signifikan pada taraf $5 \%$ (jika nilai Sig. (2-tailed) hasil perhitungan $<0,05$ ) , selanjutnya digunakan sebagai dasar penggambaran fishbone diagram [13].

\section{HASIL DAN DISKUSI}

\section{Identifikasi Waste}

Gambaran distribusi jawaban responden terhadap kecenderungan memilih dapat dilihat pada Gambar 2.

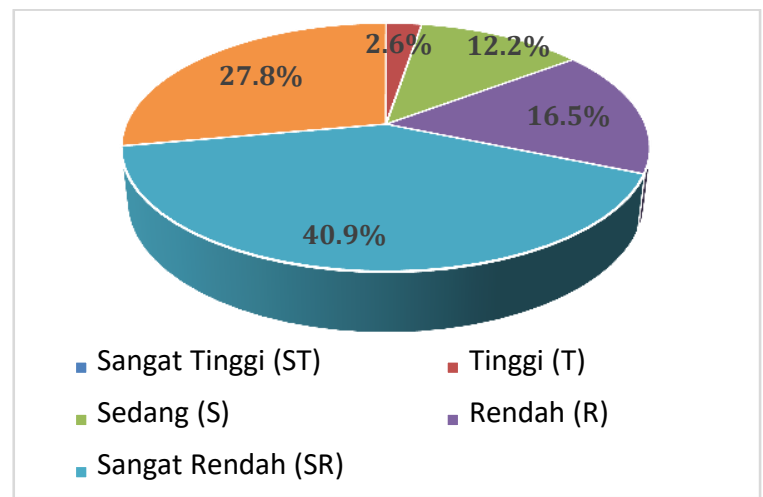

Gambar 2. Distribusi Jawaban Responden

Dari 17 jenis waste material (Tabel 1), secara umum responden cenderung memilih bahwa potensi munculnya item waste pada proyek perumahan di

Pekanbaru yaitu pada skala rendah $(40,9 \%)$, sangat rendah $(27,8 \%)$, sedang $(16,5 \%)$, tinggi $(12,2 \%)$ dan sangat tinggi $(2,6 \%)$. Namun hasil tersebut perlu dikategorikan kembali untuk melihat posisi masing-masing item waste material.

Untuk mencari nilai total, maka masing masing frekuensi item waste dikalikan dengan nilainya ( $\mathrm{ST}=5, \mathrm{~T}=4, \mathrm{~S}=3, \mathrm{R}=2$ dan $\mathrm{SR}=1$ ). Selanjutnya nilai total dikategorisasikan dengan ketentuan rumus (1).

Skor maksimum $=1 \times 5 \times 8=40$

Skor minimum $=1 \times 1 \times 8=8$

$$
\text { Range }=\left(\frac{40-8}{5}\right)-1=5,4 \sim 6
$$

Denga mengacu pada skor minimum, maksimum dan range, maka kategorisasi skor nilai total potensi waste dapat dibagi kedala skala berikut:

- Sangat Sering/ Tinggi (SS/ST) : $34-40$

- Sering/ Tinggi (S/T) : 27,5-33,5

- Cukup/Sedang (C/S) : $21-27$

- Jarang/Rendah (J/R) : 14,5-20,5

- Sangat Jarang/ Rendah (SJ/SR) : 8 - 14

Tabel 2. Identifikasi Potensi Waste

\begin{tabular}{|c|c|c|c|c|c|c|c|c|c|c|c|c|c|c|c|c|c|c|}
\hline \multirow{3}{*}{ No } & \multirow{3}{*}{$\begin{array}{c}\text { Waste } \\
\text { Material }\end{array}$} & \multicolumn{17}{|c|}{ Potensi Waste } \\
\hline & & \multicolumn{3}{|c|}{ ST } & \multicolumn{3}{|c|}{$\mathbf{T}$} & \multicolumn{3}{|c|}{$\mathbf{S}$} & \multicolumn{3}{|c|}{$\mathbf{R}$} & \multicolumn{3}{|c|}{ SR } & \multirow{2}{*}{ Total } & \multirow{2}{*}{ Kategori } \\
\hline & & $\mathbf{F}$ & $\mathbf{N}$ & $\sum$ & $\mathbf{F}$ & $\mathbf{N}$ & $\sum$ & $\mathbf{F}$ & $\mathbf{N}$ & $\sum$ & $\mathbf{F}$ & $\mathbf{N}$ & $\Sigma$ & $\mathbf{F}$ & $\mathbf{N}$ & $\Sigma$ & & \\
\hline 1 & Kayu & 0 & 5 & 0 & 2 & 4 & 8 & 2 & 3 & 6 & 3 & 2 & 6 & 1 & 1 & 1 & 21 & Sedang \\
\hline 2 & Keramik & 0 & 5 & 0 & 1 & 4 & 4 & 0 & 3 & 0 & 6 & 2 & 12 & 1 & 1 & 1 & 17 & Rendah \\
\hline 3 & Genteng & 0 & 5 & 0 & 1 & 4 & 4 & 0 & 3 & 0 & 7 & 2 & 14 & 0 & 1 & 0 & 18 & Rendah \\
\hline 4 & Besi Beton & 0 & 5 & 0 & 2 & 4 & 8 & 1 & 3 & 3 & 3 & 2 & 6 & 2 & 1 & 2 & 19 & Rendah \\
\hline 5 & Cat & 0 & 5 & 0 & 1 & 4 & 4 & 1 & 3 & 3 & 4 & 2 & 8 & 2 & 1 & 2 & 17 & Rendah \\
\hline 6 & Tanah & 1 & 5 & 5 & 1 & 4 & 4 & 0 & 3 & 0 & 1 & 2 & 2 & 5 & 1 & 5 & 16 & Rendah \\
\hline 7 & Batu & 0 & 5 & 0 & 2 & 4 & 8 & 1 & 3 & 3 & 3 & 2 & 6 & 2 & 1 & 2 & 19 & Rendah \\
\hline 8 & Pasir & 0 & 5 & 0 & 1 & 4 & 4 & 3 & 3 & 9 & 2 & 2 & 4 & 2 & 1 & 2 & 19 & Rendah \\
\hline
\end{tabular}




\begin{tabular}{|c|c|c|c|c|c|c|c|c|c|c|c|c|c|c|c|c|c|c|}
\hline 9 & Beton & 1 & 5 & 5 & 1 & 4 & 4 & 1 & 3 & 3 & 1 & 2 & 2 & 3 & 1 & 3 & 17 & Rendah \\
\hline 10 & $\begin{array}{l}\text { Cardboard } \\
\text { packaging }\end{array}$ & 0 & 5 & 0 & 0 & 4 & 0 & 1 & 3 & 3 & 1 & 2 & 2 & 1 & 1 & 1 & 6 & $\begin{array}{l}\text { Sangat } \\
\text { Rendah }\end{array}$ \\
\hline 11 & Plastik & 0 & 5 & 0 & 0 & 4 & 0 & 1 & 3 & 3 & 1 & 2 & 2 & 2 & 1 & 2 & 7 & $\begin{array}{l}\text { Sangat } \\
\text { Rendah }\end{array}$ \\
\hline 12 & Plesteran & 0 & 5 & 0 & 1 & 4 & 4 & 2 & 3 & 6 & 3 & 2 & 6 & 2 & 1 & 2 & 18 & Rendah \\
\hline 13 & Каса & 0 & 5 & 0 & 0 & 4 & 0 & 1 & 3 & 3 & 3 & 2 & 6 & 3 & 1 & 3 & 12 & $\begin{array}{l}\text { Sangat } \\
\text { Rendah }\end{array}$ \\
\hline 14 & Metal & 0 & 5 & 0 & 0 & 4 & 0 & 1 & 3 & 3 & 2 & 2 & 4 & 0 & 1 & 0 & 7 & $\begin{array}{l}\text { Sangat } \\
\text { Rendah }\end{array}$ \\
\hline 15 & Aspal & 0 & 5 & 0 & 1 & 4 & 4 & 0 & 3 & 0 & 1 & 2 & 2 & 1 & 1 & 1 & 7 & $\begin{array}{l}\text { Sangat } \\
\text { Rendah }\end{array}$ \\
\hline 16 & Plafond & 0 & 5 & 0 & 0 & 4 & 0 & 1 & 3 & 3 & 3 & 2 & 6 & 4 & 1 & 4 & 13 & $\begin{array}{l}\text { Sangat } \\
\text { Rendah }\end{array}$ \\
\hline 17 & $\begin{array}{l}\text { Batu bata } \\
\text { Jumlah }\end{array}$ & $\begin{array}{l}1 \\
3\end{array}$ & $\begin{array}{c}5 \\
85\end{array}$ & $\begin{array}{c}5 \\
15\end{array}$ & $\begin{array}{c}0 \\
14\end{array}$ & $\begin{array}{c}4 \\
68\end{array}$ & $\begin{array}{c}0 \\
56\end{array}$ & $\begin{array}{c}3 \\
19\end{array}$ & $\begin{array}{c}3 \\
51\end{array}$ & $\begin{array}{c}9 \\
57\end{array}$ & $\begin{array}{c}3 \\
47\end{array}$ & $\begin{array}{c}2 \\
34\end{array}$ & $\begin{array}{c}6 \\
94\end{array}$ & $\begin{array}{c}1 \\
32\end{array}$ & $\begin{array}{c}1 \\
17\end{array}$ & $\begin{array}{c}1 \\
32\end{array}$ & $\begin{array}{c}21 \\
254\end{array}$ & Sedang \\
\hline
\end{tabular}

Hasil identifikasi waste material pada Tabel 2 memperlihatkan bahwa potensi waste pada proyek perumahan di Pekanbaru secara umum berada pada kategori rendah $(52,9 \%)$, sangat rendah $(35,3 \%)$ dan sedang $(11,8 \%)$. Tidak terdapat waste material yang berada pada kategori tinggi dan sangat tinggi. Dari Tabel 1 juga terlihat hanya terdapat 2 material yang masuk kategori (berpotensi) sedang yaitu material kayu dan batu bata. Sembilan material kategori rendah, yaitu material keramik, genteng, besi beton, cat, tanah, batu, pasir dan plesteran. Sisanya 6 material yang berpotensi sangat rendah yaitu cardboard packaging, plastic, kaca, metal, aspal dan plafond.

\section{Penyebab Waste Berdasakan Sumberdaya}

Pada SPSS (alat bantu yang digunakan dalam analisis), ada 2 (dua) bagian penting pada outputnya yaitu besaran koefisien korelasi yang mengukur validitas dan Cronbach's Alpha. Koefisien korelasi mengukur validitas yaitu Corrected Item Total Correlation, sedangkan Cronbach's Alpha berfungsi dalam menentukan reliable atau tidaknya item kuisioner yang diujikan. Hasil analisa statistik untuk uji validitas dapat dilihat pada Tabel 3 berikut.

Tabel 3. Item-Total Statistics

\begin{tabular}{|c|c|c|c|c|c|c|}
\hline Variabel & $\begin{array}{l}\text { Code } \\
\text { Item }\end{array}$ & $\begin{array}{l}\text { Corrected Item- } \\
\text { Total Correlation }\end{array}$ & Remarks & $\begin{array}{c}\text { Cronbach's } \\
\text { Alpha }\end{array}$ & $\begin{array}{c}\text { Average } \\
\text { Cronbach's } \\
\text { Alpha } \\
\end{array}$ & Remarks \\
\hline \multirow[t]{8}{*}{ Manpower } & Man1 & .589 & invalid & .834 & \multirow{8}{*}{0.851} & \multirow{8}{*}{ reliable } \\
\hline & Man2 & .851 & valid & .798 & & \\
\hline & Man3 & .852 & valid & .796 & & \\
\hline & Man4 & .707 & valid & .820 & & \\
\hline & Man5 & .369 & invalid & .858 & & \\
\hline & Man6 & .662 & invalid & .828 & & \\
\hline & Man7 & .864 & valid & .802 & & \\
\hline & Man8 & -.093 & invalid & .900 & & \\
\hline \multirow[t]{5}{*}{ Material } & Mat1 & .893 & valid & .889 & \multirow{5}{*}{0.925} & \multirow{5}{*}{ reliable } \\
\hline & Mat2 & .796 & valid & .909 & & \\
\hline & Mat3 & .862 & valid & .896 & & \\
\hline & Mat4 & .621 & invalid & .940 & & \\
\hline & Mat5 & .857 & valid & .897 & & \\
\hline \multirow[t]{5}{*}{ Metode } & Met1 & .910 & valid & .934 & \multirow{5}{*}{0.952} & \multirow{5}{*}{ reliable } \\
\hline & Met2 & .922 & valid & .936 & & \\
\hline & Met3 & .866 & valid & .942 & & \\
\hline & Met4 & .796 & valid & .954 & & \\
\hline & Met5 & .906 & valid & .938 & & \\
\hline \multirow{5}{*}{ Alat/Mesin } & Al1 & .896 & valid & .924 & \multirow{5}{*}{0.944} & \multirow{5}{*}{ reliable } \\
\hline & $\mathrm{Al} 2$ & .782 & valid & .942 & & \\
\hline & $\mathrm{Al} 3$ & .835 & valid & .933 & & \\
\hline & $\mathrm{Al} 4$ & .844 & valid & .931 & & \\
\hline & Al5 & .917 & valid & .920 & & \\
\hline \multirow[t]{4}{*}{ Environment } & Env1 & .566 & invalid & .817 & \multirow{4}{*}{0.824} & \multirow{4}{*}{ reliable } \\
\hline & Env2 & .794 & valid & .710 & & \\
\hline & Env3 & .550 & invalid & .822 & & \\
\hline & Env4 & .701 & invalid & .755 & & \\
\hline
\end{tabular}




\section{Validitas}

Nilai $r$ tabel adalah $=0,707$, diperoleh dengan melihat table $r$ dimana $\mathrm{N}=8$ dengan signifikan 5\% (lihat lampiran distribusi nilai $r$ table dimana signifikan $0,05, \mathrm{~N}=8$ ). Jika dibandingkan dengan nilai $r$ tabel, maka nilai-nilai hasil perhitungan pada Tabel 3 menunjukkan bahwa secara umum terdapat 70,37\% item teridentifikasi valid (19 item dari 27 item), dimana nilai $r$ hitung $>0,707$ ). Dari 19 item yang valid, terdapat 4 indikator kategori waste manpower, 4 indikator kategori waste material, 5 indikator kategori waste metode, 5 indikator kategori waste alat/mesin, dan hanya 1 indikator kategori lingkungan (environment) yang teridentifikasi valid.

Indikator manpower yang valid yaitu; tidak / kurang pengalaman kerja, pemasok /supplier terlambat mengirim barang, tidak mengikuti prosedur kerja, adanya keterbatasan fisik / cidera lama, pemasok (supplier) terlambat mengirim barang. Indikator material yang valid yaitu; pembelian material tidak sesuai dengan spesifikasi, material rusak, kualitas material rendah/buruk, penyimpanan material yang buruk. Indikator metode yang valid yaitu; SOP tidak ada, inkonsisten metode kerja, metode konstruksi yang digunakan tidak tepat/tidak sesuai, perubahan desain, perencanaan dan penjadwalan yang buruk. Indikator alat/mesin yang valid yaitu; alat rusak, perbaikan alat membutuhkan waktu yang cukup lama, alat yang digunakan tidak sesuai, alat terlalu konvensional / kuno, dan alat kurang. Sedangkan untuk indicator lingkungan hanya satu yaitu komplain masyarakat yang valid. Hal tersebut disebabkan karena adanya aktifitas pembangunan membuat jalan lingkungan sekitar area lokasi perumahan kotor dan agak rusak.

\section{Reliabilitas}

Dikatakan reliabel jika nilai alfa hasil hitung pada Tabel 3 lebih besar dari standar yang digunakan yaitu alpha > 0.70 (sufficient reliability). Hasil penelitian menunjukkan bahwa nilai setiap item indikator berada antara 0,7 sampai dengan > 0,9 . Artinya semua indikator memiliki nilai reliabilitas antara mencukupi dan sempurna. Sedangkan secara general dapat dikatakan bahwa semua variable pertanyaan adalah reliabel dengan tingkat kuat hingga sempurna $(>0,8 \mathrm{sd}>0,9)$.

\section{Keeratan hubungan Penyebab Waste}

Hasil SPSS dengan korelasi pearson yang menunjukkan keeratan hubungan indikator dengan variabelnya dapat dilihat pada Tabel 4.

Secara umum kekuatan hubungan item-item yang diuji berada pada korelasi kuat dan sangat kuat, hanya terdapat 1 item yang berkorelasi sangat lemah yaitu item teamwork yang kurang / tidak solid (Man8).

Tabel 4. Nilai Korelasi dan Signifikansi

\begin{tabular}{|c|c|c|c|c|}
\hline Variabel & Kode Item & $\begin{array}{c}\text { Total Correlation } \\
\text { Coefficient }\end{array}$ & $\begin{array}{c}\text { Kekuatan } \\
\text { Hubungan }\end{array}$ & $\begin{array}{c}\text { Sig. } \\
\text { (2-tailed) }\end{array}$ \\
\hline \multirow[t]{8}{*}{ Manpower } & Man1 & $0,732^{*}$ & kuat & 0,039 \\
\hline & Man2 & $0,827^{*}$ & sangat kuat & 0,011 \\
\hline & Man3 & $0,856^{* *}$ & sangat kuat & 0,007 \\
\hline & Man4 & 0,689 & kuat & 0,059 \\
\hline & Man5 & 0,531 & kuat & 0,176 \\
\hline & Man6 & 0,634 & kuat & 0,092 \\
\hline & Man7 & $0,870^{* *}$ & sangat kuat & 0,005 \\
\hline & Man8 & 0,030 & sangat lemah & 0,934 \\
\hline \multirow[t]{5}{*}{ Material } & Mat1 & $0,913^{* *}$ & sangat kuat & 0,002 \\
\hline & Mat2 & $0,853^{* *}$ & sangat kuat & 0,010 \\
\hline & Mat3 & $0,913^{* *}$ & sangat kuat & 0,002 \\
\hline & Mat4 & $0,786^{*}$ & sangat kuat & 0,021 \\
\hline & Mat5 & $0,932 * *$ & sangat kuat & 0,001 \\
\hline \multirow[t]{5}{*}{ Metode } & Met1 & $0,969^{* *}$ & sangat kuat & 0,000 \\
\hline & Met2 & $0,871^{* *}$ & sangat kuat & 0,005 \\
\hline & Met3 & $0,906^{* *}$ & sangat kuat & 0,002 \\
\hline & Met4 & $0,745^{*}$ & kuat & 0,034 \\
\hline & Met5 & $0,920^{* *}$ & sangat kuat & 0,001 \\
\hline \multirow[t]{5}{*}{ Alat/Mesin } & $\mathrm{Al} 1$ & $0,914^{* *}$ & sangat kuat & 0,001 \\
\hline & $\mathrm{Al} 2$ & $0,791^{*}$ & sangat kuat & 0,019 \\
\hline & $\mathrm{Al} 3$ & $0,945^{*}$ & sangat kuat & 0,000 \\
\hline & Al4 & $0,889 * *$ & sangat kuat & 0,003 \\
\hline & Al5 & $0,964^{* *}$ & sangat kuat & 0,000 \\
\hline \multirow{4}{*}{ Environment } & Env1 & $0,858 * *$ & sangat kuat & 0,006 \\
\hline & Env2 & $0,788^{*}$ & sangat kuat & 0,020 \\
\hline & Env3 & $0,793^{*}$ & sangat kuat & 0,019 \\
\hline & Env4 & $0,793^{*}$ & sangat kuat & 0,019 \\
\hline
\end{tabular}


Dalam menentukan layak atau tidaknya suatu item digunakan, dilakukan juga uji signifikansi koefisien korelasi pada taraf signifikansi 5\%. Signifikansi bisa ditentukan oleh Sig. (2-tailed). Jika nilai Sig. (2-tailed) < 0,05, maka hubungan yang terdapat pada $r$ dianggap signifikan. Hasil uji signifikansi dengan korelasi pearson pada Tabel 4 menunjukkan bahwa hampir seluruh item (23 item) memiliki nilai Sig. (2-tailed) $<0,05$. Artinya itemitem tersebut berkonstribusi besar sebagai faktor penyebab waste pada proyek perumahan di Pekanbaru. Ke 23 item tersebut selanjutnya dijadikan dasar dalam pembuatan fishbone diagram dengan terlebih dahulu merangking skornya. Hasil perangkingan skor ke 23 item indikator tersebut dapat dilihat pada Tabel 5 .

Tabel 5. Skor Indikator Penyebab Waste

\begin{tabular}{|c|c|c|c|c|}
\hline Variabel & Item Indikator & Kode & $\begin{array}{l}\text { Score } \\
\text { Level }\end{array}$ & $\begin{array}{l}\text { Average } \\
\text { Score }\end{array}$ \\
\hline \multirow{4}{*}{ Manpower } & Pemasok (supplier) terlambat mengirim barang & Man 7 & 0,870 & \multirow{4}{*}{0,821} \\
\hline & Tidak mengikuti prosedur kerja. & Man 3 & 0,856 & \\
\hline & Tidak/ kurang pengalaman kerja. & Man 2 & 0,827 & \\
\hline & Skill yang rendah & Man 1 & 0,732 & \\
\hline \multirow{5}{*}{ Material } & Penyimpanan material yang buruk & Mat 5 & 0,932 & \multirow{5}{*}{0,866} \\
\hline & Pembelian material tidak sesuai dengan spesifikasi & Mat 1 & 0,913 & \\
\hline & Kualitas material rendah/buruk & Mat 3 & 0,913 & \\
\hline & Material rusak & Mat 2 & 0,853 & \\
\hline & Keterlambatan material tiba di lokasi & Mat 4 & 0,786 & \\
\hline \multirow{5}{*}{ Metode } & SOP tidak ada & Met 1 & 0,969 & \multirow{5}{*}{0,873} \\
\hline & Perencanaan dan penjadwalan yang buruk & Met 5 & 0,920 & \\
\hline & $\begin{array}{l}\text { Metode konstruksi yang digunakan tidak } \\
\text { tepat/tidak sesuai. }\end{array}$ & Met 3 & 0,906 & \\
\hline & $\begin{array}{l}\text { Inkonsisten metode kerja (metode kerja berubah- } \\
\text { ubah). }\end{array}$ & Met 2 & 0,871 & \\
\hline & Perubahan desain & Met 4 & 0,745 & \\
\hline \multirow{5}{*}{ Alat } & Alat kurang & Al 5 & 0,964 & \multirow{5}{*}{0,885} \\
\hline & Alat yang digunakan tidak sesuai. & Al 3 & 0,945 & \\
\hline & Alat rusak & Al 1 & 0,914 & \\
\hline & Alat terlalu konvensional/ kuno & $\mathrm{Al} 4$ & 0,889 & \\
\hline & Perbaikan alat membutuhkan waktu yang lama. & $\mathrm{Al} 2$ & 0,791 & \\
\hline \multirow{4}{*}{ Environment } & Cuaca (hujan) & Env 1 & 0,858 & \multirow{4}{*}{0,808} \\
\hline & Kondisi lokasi & Env 3 & 0,793 & \\
\hline & Kerusakan/kehilangan akibat pihak lain & Env 4 & 0,793 & \\
\hline & Masyarakat yang complain & Env 2 & 0,788 & \\
\hline
\end{tabular}

Bedasarkan hasil analisis Table 5 di atas, nilai rata-rata skor tertinggi dari 5 variabel penyebab waste yaitu variable alat/masin. Variabel tersebut memberikan konstribusi sebesar 0,885. Artinya, variabel alat memberikan pengaruh yang paling besar dalam menimbulkan waste. Hal tersebut secara umum disebabkan oleh adanya alat yang kurang saat bekerja, alat yang digunakan tidak sesuai dengan kebutuhan, alat rusak, alat kuno dan waktu untuk perbaikan alat terkadang membutuhkan waku yang cukup lama. Variabel selanjutnya yang berkonstribusi yaitu metode sebesar 0,873, material sebesar 0,866 dan manpower sebesar 0,821. Variabel yang berkonstribusi paling rendah yaitu environment/lingkungan sebesar 0,808. Meskipun responden secara umum berpendapat bahwa faktor cuaca memberikan pengaruh yang paling besar pada variable tersebut, namun menjadi paling rendah diantara ke 5 variabel waste karena ada kemungkinan pengambilan data yang dilakukan pada saat musim kering.

Urutan dan nilai tingkat penyebab waste pada proyek perumahan di Pekanbaru digambarkan pada fishbone berikut. 


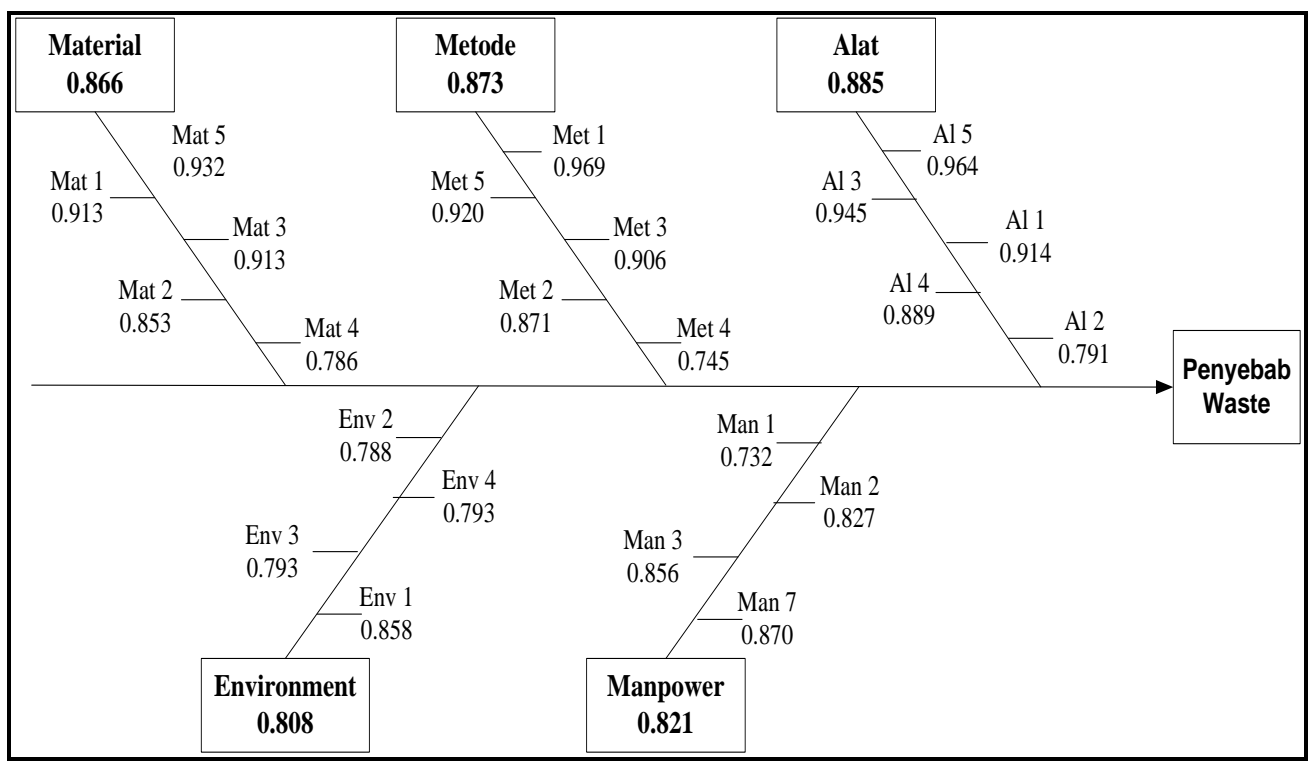

Gambar 4. Fishbone Diagram Faktor Penyebab Waste

Fishbone diagramatau yang juga dikenal sebagai diagram Ishikawa di atas menunjukkan penyebab-penyebab dari event-eventyang spesifik sehingga mengakibatkan waste pada proyek perumahan di Pekanbaru. Alat/mesin menjadi variable utama yang menyebabkan waste, yang diikuti oleh metode, material, tenaga kerja (manpower) dan terkahir lingkungan (environment). Keterkaitan antara satu variabel dengan variable yang lain juga harus menjadi perhatian. Indikator pada variable alat, metode dan material dapat memunculkan waste pada manpower. Misalnya, jika alat kurang, terlalu konvensional, rusak dan tidak sesuai dengan kebutuhan, maka akan mempengaruhi produktivitas manpower. Hal tersebut karena dapat menjadi penyebab waste waktu pada manpower. Metode yang tidak tepat, perencanaan yang buruk, SOP tidak ada, metode kerja yang berubah-ubah, perubahan desain juga dapat menyebabkan waste pada manpower. Begitu juga dengan material. Penyimpanan material yang tidak baik, material rusak, kualitas yang rendah/buruk dan pengirimannya yang lambat juga sangat berpengaruh pada produktivitas manpower. Disisi lain manpower juga dapat menyebabkan waste pada variable lainnya. Misalnya perlakuan/tindakan kasar pekerja saat memindahkan material menjadi penyebab material terbuang (misalnya pada bata), kecerobohan pengukuran/pemotongan (misalnya pada material besi dan bekisting), skill yang rendah menyebabkan pekerjaan perbaikan (rework) sehingga dibutuhkan material baru, dll. Terkait hal tersebut penting bagi tenaga kerja untuk meningkatkan skill dan menambah pengalaman mereka, salah satunya yaitu dengan mengikuti pelatihan (training) agar dapat meningkatkan produktivitas di lapangan.

\section{KESIMPULAN}

Secara keseluruhan, hasil identifikasi terhadap material yang berpotensi ditemui pada proyek pembangunan perumahan di Pekanbaru yaitu material kayu dan batu bata (berpotensi sedang), material keramik, genteng, besi beton, cat, tanah, batu, pasir dan plesteran (berpotensi rendah) dan, cardboard packaging, plastik, kaca, metal, aspal dan plafond (berpotensi sangat rendah). Terdapat beberapa variable penyebab waste. Variabelvariabel tersebut terkait dengan sumber daya yang dibutuhkan selama proses pengerjaan proyek. Sumber penyebab waste selama proses produksi yaitu secara signifikan dipengaruhi oleh variabel alat/mesin, metode kerja, material, manpower dan lingkungan. Satu sumber variabel dapat mempengaruhi variabel yang lain, sehingga sangat penting untuk memperhatikan penyebab waste agar produktivitas pekerjaan dilapangan tidak terganggu.

\section{REFERENSI}

[1] L. Koskela, "CIFECENTER for Integrated Facility Engineering Aplication of the new product philosophy to construction," Standford University, Finland, 1992.

[2] A. Mossman, "Creating value: A sufficient way to eliminate waste in lean design and lean production," Lean Constr. J., vol. 2009, pp. 13-23, 2009.

[3] I. P. A. Wiguna, “Analisis Penanganan Material Waste Pada Proyek Perumahan Di Surabaya," Semin. Nas. Apl. Teknol. Prasarana Wil., pp. 147-154, 2009.

[4] A. Asnudin, "Pengendalian Sisa Material Konstruksi Pada Pembangunan Rumah Tinggal," J. Mek. Tek., vol. 12, no. 3, pp. 162164, 2010.

[5] F. M. D. Setyanto. E., Kaming. P. F., "Studi Sisa Material Pada Proyek Gedung Dan Perumahan," Konf. Nas. Tek. Sipil 4 (KoNTekS 4), vol. 4, no. KoNTekS 4, pp. 235-243, 2010. 
[6] P. V. Sáez, M. Del Río Merino, C. PorrasAmores, and A. S. A. González, "Assessing the accumulation of construction waste generation during residential building construction works," Resour. Conserv. Recycl., vol. 93, no. 2014, pp. 67-74, 2014.

[7] S. Dinesh, R. Sethuraman, and S. Shivaprakasam, "the Review on Lean Construction an Effective Approach in Construction," Int. J. Eng. Res. Mod. Educ., vol. Special is, no. April, pp. 119-123, 2017.

[8] Lean Construction Institute, "Pengertian \& Fokus Pilar Lean Construction." [Online]. Available:

https://leanconstructionindonesia.com/201 8/08/27/pengertian-fokus-pilar-leanconstruction/.

[9] H. K. Mohajan, "Two Criteria for Good Measurements in Research: Validity and Reliability," Ann. Spiru Haret Univ. Econ. Ser., vol. 17, no. 4, pp. 59-82, 2017.

[10] I. Ghozali, Aplikasi multivariate program SPSS. 2009.

[11] S. Tumpal JR Sitinjak, Lisrel. Graha Ilmu, 2006.

[12] J. Sarwono, Metode Penelitian Kuantitatif \& Kualitatif, Pertama. Yogyakarta: Graha Ilmu, 2006.

[13] Elizar, M. A. Wibowo, and P. Koestalam, "Identification and analyze of influence level on waste construction management of performance," Procedia Eng., vol. 125, pp. 46-52, 2015.

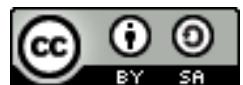

This is an open access article which means that all content is freely available without charge to the user or his/her institution. Jurnal Saintis allows the author(s) to hold the copyright without restriction. The copyright in the text of individual rticles (including research article, opinion articles, and abstracts) is the property of their respective authors distriuted under the terms of the Creative Commons Attribution-ShareAlike 4.0 International License (http://creativecommons.org/licenses/by-sa/4.0/) which permits unrestricted use, distribution, and reproduction in any medium. Users are allowed to read, download, copy, distribute, search, or link to full-text articles in this journal without asking by giving appropriate credit, provide a link to the license, and indicate if changes were made. 
This page is intentionally blank 